\title{
Thromboembolism Incidence and Risk Factors in Children with Cancer: A Population-Based Cohort Study
}

\author{
Marie-Claude Pelland-Marcotte ${ }^{1}$ Jason D. Pole $\mathrm{e}^{2,3}$ Ket \\ Christine Sabapathy ${ }^{7}$ Jessica Halparin ${ }^{8}$ Leonardo \\ ${ }^{1}$ Division of Haematology/Oncology, Department of Paediatrics, The \\ Hospital for Sick Children, Toronto, Ontario, Canada \\ 2 Pediatric Oncology Group of Ontario, Toronto, Ontario, Canada \\ ${ }^{3}$ Program in Child Health Evaluative Sciences, The Hospital for Sick \\ Children, Peter Gilgan Centre for Research and Learning, Toronto, \\ Ontario, Canada \\ ${ }^{4}$ Division of Haematology-Oncology, Department of Pediatrics, IWK \\ Health Centre, Halifax, Nova Scotia, Canada \\ ${ }^{5}$ Division of Haematology/Oncology, Department of Pediatrics, \\ McMaster Children's Hospital, Hamilton, Ontario, Canada \\ ${ }^{6}$ Division of Pediatric Haematology/Oncology, Department of Pediatrics, \\ Royal University Hospital, University of Saskatchewan, Saskatoon, Canada \\ ${ }^{7}$ Division of Pediatric Haematology/Oncology, Department of \\ Pediatrics, McGill University, Montréal, Québec, Canada \\ ${ }^{8}$ Division of Haematology/Oncology/BMT, British Columbia \\ Children's Hospital, Vancouver, British Columbia, Canada
}

Ketan Kulkarni ${ }^{4} \quad$ Uma Athale ${ }^{5}$ David Stammers ${ }^{6}$

Thromb Haemost 2018;118:1646-1655.

\begin{abstract}
Address for correspondence Marie-Claude Pelland-Marcotte, MD, Division of Haematology/Oncology, The Hospital for Sick Children, 555 University Avenue, Toronto, Ontario M5G 1X8, Canada (e-mail: marie-claude.pelland-marcotte@sickkids.ca).
\end{abstract}

received

May 2, 2018

accepted after revision

July 11, 2018
There is conflicting information about the epidemiology of thromboembolism (TE) in paediatric oncology. Objectives were to describe the incidence and risk factors of TE in children with cancer. We included all children with cancer less than 15 years of age diagnosed from 2001 to 2016, treated at one of the 12 Canadian paediatric centres outside of Ontario and entered into the Cancer in Young People-Canada database. Potential risk factors for TE were evaluated using Cox proportional hazards regression stratified by haematological malignancies versus solid tumours. Factors associated with vascular accessand non-vascular access-related TE were compared using chi-square or Fisher's exact tests. Of the 7,471 children included, 283 experienced TE requiring medical intervention; cumulative incidence of TE at 5 years was $3.8 \pm 0.2 \%$ and $0.36 \% \pm 0.07 \%$ for lifethreatening or fatal TE. For haematological malignancies, the following factors were associated with TE in multivariable regression: age $<1$ year, 5 to 9.99 years and 10 to 14.99 years (relative to age $1-4.99$ years), haematopoietic stem cell transplant (hazard ratio $[\mathrm{HR}]=1.49,95 \%$ confidence interval $[\mathrm{Cl}], 1.00-2.32)$, anthracyclines $(\mathrm{HR}=2.21,95 \% \mathrm{Cl}$, $1.12-4.37)$ and asparaginase $(\mathrm{HR}=1.68,95 \% \mathrm{Cl}, 1.15-2.44)$. For solid tumours, obesity $(\mathrm{HR}=1.92,95 \% \mathrm{Cl}, 1.01-3.68)$, surgery $(\mathrm{HR}=2.70,95 \% \mathrm{Cl}, 1.44-5.08)$, radiation $(\mathrm{HR}=47.51,95 \% \mathrm{Cl}, 24.01-94.01)$, anthracyclines $(\mathrm{HR}=2.74,95 \% \mathrm{Cl}, 1.29-5.82)$ and platinum agents ( $\mathrm{HR}=2.26,95 \% \mathrm{Cl}, 1.19-4.28)$ were associated with TE. Life-threatening and fatal TEs were more common among non-vascular access TEs (14.5\% vs. $3.3 \%$ $p=0.001)$. In a population-based cohort, $4 \%$ of children with cancer developed a clinically significant TE. Accurate risk stratification tools are needed specific to malignancy type.
- epidemiology (c) 2018 Georg Thieme Verlag KG Stuttgart - New York
DOI https://doi.org/ 10.1055/s-0038-1668543. ISSN 0340-6245. 


\section{Introduction}

Thromboembolism (TE) is a well-recognized complication in children and adults with cancer. TEs are associated with chronic morbidity, ${ }^{1-3}$ delay or modification of treatment, ${ }^{4}$ adverse events associated with anticoagulation ${ }^{5}$ and rarely mortality. ${ }^{6}$ While its epidemiology is well described in adult populations, many areas of uncertainty remain in understanding the incidence and risk factors of TE in children with cancer. Previous studies have reported a TE incidence of between 2.1 and $16 \%$ for symptomatic events in children with cancer, and up to $40 \%$ when accounting for asymptomatic events. ${ }^{7-18}$

Several risk factors have been proposed for TE in children with cancer. Previously described patient-specific factors include older age, higher body mass index (BMI), presence of thrombophilia and non-O blood group..$^{7,11,15,17-19}$ Disease and treatment-related factors include haematological malignancies and sarcomas, specific chemotherapy agents, namely, asparaginase and steroids, immobilization and surgery. ${ }^{15,16,20}$ The presence of a central venous catheter (CVC) has been associated with thrombosis, with varying rates of TEs depending of the type of catheter used and the presence of CVC-related complications such as infection or occlusion. $^{8,13}$ Haematopoietic stem cell transplant (HSCT) has been shown to create a state of acquired thrombophilia, ${ }^{21}$ and a recent study has shown that TEs are a clinically relevant complication of HSCT in children and young adults. ${ }^{22}$

Published data in children are mostly limited to singlecentre, single disease retrospective studies or prospective studies consisting of children with acute lymphoblastic leukaemia (ALL). ${ }^{7,8,11,13-19,22-27}$ A large multi-institutional study that includes all paediatric cancer types is important to improve our understanding of risk factors for TE, and to have a sufficiently large sample size allowing for robust modelling and improved precision in estimates. Therefore, our objectives were to describe the incidence of thrombosis and to identify risk factors for thrombosis among Canadian cancer patients less than 15 years of age using a population-based approach.

\section{Materials and Methods}

We conducted a retrospective, population-based study using the Cancer in Young People-Canada (CYP-C) database.

\section{Study Population}

We included patients who were: (1) less than 15 years of age at cancer diagnosis; (2) diagnosed with cancer between 1 January 2001 and 31 December 2016; (3) diagnosed with a neoplasm included in the International Classification of Childhood Cancer (ICCC), third edition; ${ }^{28}$ and (4) diagnosed and treated at one of the 12 paediatric oncology centres in Canada outside Ontario and entered into CYP-C. ICCC includes malignant neoplasms as well as non-malignant central nervous system (CNS) tumours. We excluded patients from the five Ontario centres, whose information was provided to CYP-C from the Pediatric Oncology Group of Ontario Network Information System (POGONIS), because TE events were not collected systematically over the study period in POGONIS.
Collection of data in CYP-C was approved by the Research Ethics Boards of all 12 participating sites. The Research Ethics Board at The Hospital for Sick Children approved this analysis. The requirement for informed consent was waived given the retrospective nature of the study.

\section{Data Source}

CYP-C is a population-based registry that captures all paediatric cancers diagnosed and treated in one of the 17 paediatric oncology centres of Canada for children up to 15 years of age. Almost all patients $<15$ years old with cancer are treated in one of these hospitals. Application for utilization of data was submitted through the C17 Council website (available at: http://www.c17.ca/index.php? $\mathrm{cID}=70$ ). Data are abstracted at each participating site from the medical records by trained clinical research assistants or data managers and, for the 12 centres included in this study, the data are entered directly into CYP-C. Data consist of demographics features, diagnostic details, treatment information and outcomes. Data also include specific treatment-related complications that are abstracted from the medical records. If present, grade and date of onset are recorded. Data are collected until 5 years after the primary neoplasm or any subsequent malignancies.

Multiple approaches have been taken to ensure high quality data and these approaches have been previously reported. ${ }^{29}$ In brief, data managers meet monthly by teleconference and annually in person for education and training. Each site's data are also audited regularly.

\section{Outcomes}

The primary outcome of TE was defined as an occlusion of a blood vessel and graded using the Common Terminology Criteria for Adverse Events (CTCAE), versions 3 or 4. TEs of grade 3 to 5 were included where grade 3 refers to a TE requiring medical intervention, grade 4 refers to a TE associated with haemodynamic or neurologic instability requiring an urgent intervention and grade 5 refers to a TE leading to death. TEs were categorized as either vascular access-related, if the thrombus or embolus could be attributed to the presence of a peripheral or central catheter and had developed in the region of the catheter, or not vascular access-related. Type of catheter and method of insertion were not available; thus, all vascular access-related TEs are analysed together.

\section{Exposure Variables}

Potential risk factors for TE included age at cancer diagnosis, sex, obesity, malignancy type, diagnostic era, intensity of treatment, chemotherapy (anthracyclines, asparaginase, methotrexate, platinum agents, steroids), radiation, surgery and HSCT. In addition, we did not include race or ethnicity in the analysis. Age at cancer diagnosis was divided into four categories: less than 1 year, 1 to 4.99 years, 5 to 9.99 years and 10 to 14.99 years. BMI percentile at diagnosis was calculated for all patients 2 years or older using the World Health Organization growth reference standards for BMI $z$ score (zBMI). Obesity was defined as BMI $>99.9$ percentile for age $(z \mathrm{BMI}>3)$ in children 2 to 4.99 years and $>97$ percentile for 
age $(z \mathrm{BMI}>2)$ in children 5 years and above. ${ }^{30}$ Diagnostic era was divided between 'early', if the cancer diagnosis occurred on or before 31 December 2006 and 'late' if the diagnosis was made after 31 December 2006. This date threshold, used in a previous study based on CYP-C data, ${ }^{29}$ was retained to facilitate comparisons. Intensity of treatment was classified as per the Intensity of Treatment Rating scale (ITR-3.0), ${ }^{31}$ a standardized and reliable method to classify intensity of cancer treatment protocols. Possible levels range from 0 to 4 , from 'least' to 'most intensive' treatments. Level 2, 'moderately intensive', and 3, 'very intensive', treatments were combined, based on similarity of included diagnosis and treatment modalities. Surgery was considered as a risk factor for TE if it occurred within the preceding 30 days, based on biological evidence of activation of the coagulation system for at least 4 weeks after an operation. ${ }^{32}$ All surgeries, regardless of the purpose of the intervention (oncological vs. non-oncological) were considered. Chemotherapy was captured as a dichotomous variable, if the patient was exposed to at least one dose of any chemotherapy agent. The exposure to any dose of the following agents was also collected, because of previously reported associations with TE: ${ }^{33}$ anthracyclines, asparaginase (including all formulations of asparaginase), methotrexate, platinum agents and steroids. HSCT was considered a dichotomous variable. For radiation therapy, the risk window for TE started with the first day of radiation; we did not set an end date to the risk window as there is evidence that radiationinduced vascular damage is persistent. ${ }^{34}$ Because of the systemic changes induced by radiation therapy, ${ }^{34}$ we did not discriminate between sites of radiation therapy.

\section{Statistical Plan}

Analyses were performed on data available as of 1 August 2017. Population characteristics were summarized descriptively. Univariate and multivariable Cox proportional hazards regression analyses were performed to explore the relationship between potential predictors variables and the cumulative incidence of TE. Analyses were stratified by type of malignancy (haematological malignancies vs. solid tumours) given substantial differences in rates of exposure to treatment-related risk factors, such as surgery, radiation or specific chemotherapy agents between the two groups. Haematological malignancies included leukaemias, myeloproliferative diseases, myelodysplastic diseases and lymphomas and reticuloendothelial neoplasms. Solid tumours included intra-cranial and intra-spinal neoplasms as well as extra-cranial solid tumours (neuroblastomas and other peripheral nervous cell tumours, retinoblastomas, renal tumours, hepatic tumours, malignant bone tumours, soft tissue and extraosseous sarcomas, germ cell tumours, malignant epithelial neoplasms and other malignant tumours), as defined in ICCC. ${ }^{28}$ Time to TE was defined as the number of days from first cancer diagnosis to occurrence of the first TE. For those without a TE, patients were censored on the date of last contact and death was considered a competing event. In the Cox proportional hazards models, surgery and radiation were treated as time-dependent covariates. Impact of these variables were described using hazard ratios (HRs) with corresponding 95\% confidence intervals (CIs). We examined Pearson's correlations coefficients to evaluate collinearity which guided multivariable models.

We performed a sub-group analysis among children with TE to compare factors associated with vascular-related and non-vascular-related events using Wilcoxon rank sum test, chi-square or Fisher's exact test, as appropriate. All tests were two-tailed with a $p$-value of $<0.05$ considered statistically significant. All analysis were conducted using SAS (Version 9.4, Cary, North Carolina, United States).

\section{Results}

Overall, 7,471 patients were included; - Fig. 1 illustrates the number of potential cases identified in CYP-C, the number excluded and the reasons for exclusion. Their clinical characteristics are listed in - Table $\mathbf{1}$ stratified by haematological

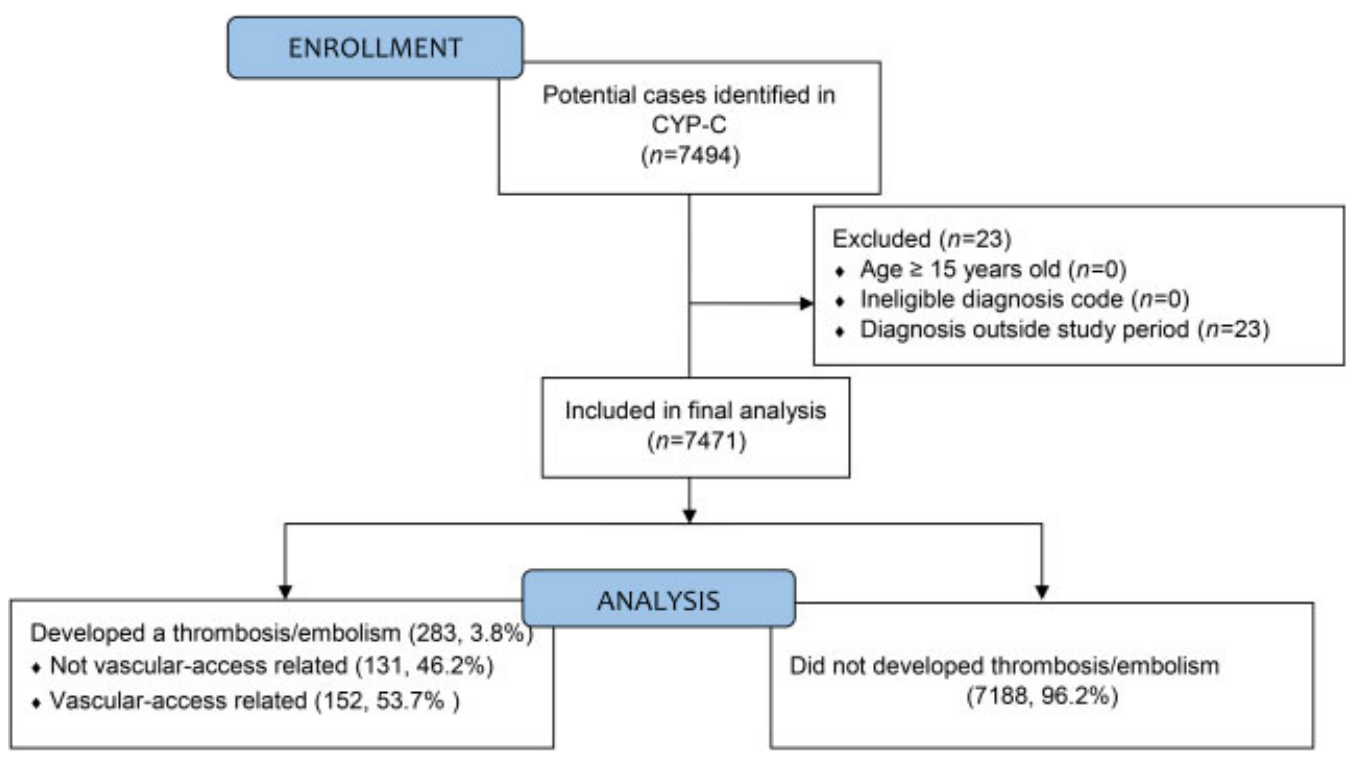

Fig. 1 Flow diagram of case identification and selection. 
Table 1 Patients characteristics ${ }^{\mathrm{a}}$

\begin{tabular}{|c|c|c|c|}
\hline Characteristics & $\begin{array}{l}\text { All patients } \\
n=7,471 \\
n(\%)\end{array}$ & $\begin{array}{l}\text { Haematological malignancies } \\
n=3,369 \\
n(\%)\end{array}$ & $\begin{array}{l}\text { Solid tumours } \\
n=4,102 \\
n(\%)\end{array}$ \\
\hline \multicolumn{4}{|l|}{ Age, y } \\
\hline Less than 1 & $796(10.7)$ & $195(5.8)$ & $601(14.7)$ \\
\hline $1-4.99$ & $2,822(37.8)$ & $1,378(40.9)$ & $1,444(35.2)$ \\
\hline $5-9.99$ & $1,907(25.5)$ & $901(26.7)$ & $1,006(24.5)$ \\
\hline $10-14.99$ & $1,946(26.0)$ & $895(26.6)$ & $1,051(25.6)$ \\
\hline Male sex & $4,034(54.0)$ & $1,916(56.9)$ & $2,118(51.6)$ \\
\hline \multicolumn{4}{|l|}{ Diagnostic era } \\
\hline Early & $3,005(40.2)$ & $1,376(40.8)$ & $1,629(39.7)$ \\
\hline Late & $4,466(59.8)$ & 1,993 (59.2) & $2,473(60.3)$ \\
\hline Obesity at diagnosis $^{\mathrm{b}}$ & $487 / 5,192(9.4)$ & $247 / 2,789(8.9)$ & $240 / 2,403(10.0)$ \\
\hline \multicolumn{4}{|l|}{ Primary diagnosis } \\
\hline Leukaemia & $2,406(32.2)$ & $2,406(71.4)$ & - \\
\hline ALL & $1,937(25.9)$ & $1,937(57.5)$ & \\
\hline AML & $317(4.2)$ & $317(9.3)$ & \\
\hline Lymphoma & $963(12.9)$ & $963(28.6)$ & - \\
\hline HD & $289(3.9)$ & $289(8.6)$ & \\
\hline NHL (incl. Burkitt) & $426(5.7)$ & $426(12.6)$ & \\
\hline CNS tumours & $1,689(22.6)$ & - & $1,689(41.2)$ \\
\hline Astrocytoma & $683(9.1)$ & & $683(16.7)$ \\
\hline Ependymoma & $185(2.5)$ & & $185(4.5)$ \\
\hline Medulloblastoma & $340(4.6)$ & & $340(10.1)$ \\
\hline Extra-cranial solid tumours & $2,413(32.3)$ & - & $2,413(58.8)$ \\
\hline Ewing sarcoma & $121(1.6)$ & & $121(2.9)$ \\
\hline Hepatoblastoma & $94(1.3)$ & & $94(2.3)$ \\
\hline Neuroblastoma & $604(8.1)$ & & $604(14.7)$ \\
\hline Osteosarcoma & $166(2.2)$ & & $166(4.0)$ \\
\hline Rhabdomyosarcoma & $223(3.0)$ & & $223(5.4)$ \\
\hline Wilms tumour & $396(5.3)$ & & $396(9.7)$ \\
\hline \multicolumn{4}{|l|}{ ITR } \\
\hline 0 & $305(4.1)$ & $111(3.3)$ & $194(4.7)$ \\
\hline 1 & $878(11.7)$ & $87(2.6)$ & $791(19.3)$ \\
\hline $2 / 3$ & $4,927(66.0)$ & $2,478(73.5)$ & $2,449(59.7)$ \\
\hline 4 & $1,361(18.2)$ & $693(20.6)$ & $668(16.3)$ \\
\hline Radiation therapy & $2,059(27.6)$ & $521(15.5)$ & $1,538(37.5)$ \\
\hline Surgery & $3,900(52.2)$ & 469 (13.9) & $3,431(83.6)$ \\
\hline HSCT & $771(10.3)$ & $410(12.2)$ & $361(8.8)$ \\
\hline Chemotherapy (any agents) & $5,888(78.8)$ & $3,173(94.2)$ & $2,715(66.2)$ \\
\hline Anthracyclines & $3,904(52.3)$ & $2,795(83.0)$ & $1,109(27.0)$ \\
\hline Asparaginase & $2,116(28.3)$ & $2,112(62.7)$ & $<5$ \\
\hline Steroids & $4,179(55.9)$ & $2,883(85.6)$ & $1,296(31.6)$ \\
\hline Systemic methotrexate & $2,523(33.8)$ & $2,270(67.4)$ & $253(6.2)$ \\
\hline Platinum compounds & $941(12.6)$ & $23(0.7)$ & $918(22.4)$ \\
\hline
\end{tabular}

Abbreviations: ALL, acute lymphoblastic leukaemia; AML, acute myeloid leukaemia; CNS, central nervous system; HD, Hodgkin lymphoma; $\mathrm{HSCT}$, haematopoietic stem cell transplantation; ITR, Intensity Treatment Rating; NHL, non-Hodgkin lymphoma.

${ }^{\text {a}}$ Small cell sizes suppressed and listed as $<5$.

${ }^{\mathrm{b}}$ Obesity assessed in those 2 years of age and older with height and weight available at diagnosis. 
malignancies versus solid tumours. The median age at diagnosis of the total cohort was 5.0 years (range: $0.0-14.9$ ) and was similar in patients with haematological malignancies (median [range]: 5.0 years [0.0-14.9]) and solid tumours (median [range]: 5 years [0.0-14.9]). Among the entire cohort, 283 patients developed at least one TE. Most TEs were grade 3 (259, $91.5 \%)$, with 18 (6.4\%) grade 4 and $6(2.1 \%)$ grade 5. One patient was not included in cumulative incidence analyses because the date of TE was missing. The cumulative incidence of TE ( \pm standard error [SE]) at 5 years from cancer diagnosis was $3.8 \pm 0.2 \%$. The median interval (interquartile range) between date of cancer diagnosis and development of TE was 77 days (18-166 days). The cumulative incidence $( \pm \mathrm{SE})$ of life-threatening or fatal TE (i.e. TE grade 4 or 5 ) was $0.36 \pm 0.07 \%$ at 5 years. Five out of the six TE-related deaths were not vascular access-related and occurred in patients older than 10 years old, with either haematological malignancies or CNS tumours.

The proportion of patients with TE was highest in children with leukaemia $(135 / 2,406,5.6 \%)$, lowest in children with CNS tumours $(17 / 1,689,1.0 \%)$ and intermediate in children with lymphomas $(4.4 \%, 42 / 963)$ and extra-cranial solid tumours (89/2,413, 3.7\%). The extra-cranial solid tumours most commonly associated with TEs were neuroblastomas $(n=20)$, nephroblastomas $(n=19)$ and osteosarcomas $(n=14)$.

\section{Risk Factors for Thrombosis}

- Table 2 shows the results of univariate and multivariable Cox proportional hazards regression for 3,368 patients with 177 TEs among those with haematological malignancies. In univariate analysis, the following factors were significantly associated with TE: age at cancer diagnosis, HSCT, ITR, anthracyclines, asparaginase, methotrexate and steroids. A total of $580(17.2 \%)$ patients had missing BMI values, either because they were aged $<2$ years or because either weight or height at diagnosis were missing. We therefore conducted a secondary multivariable regression analysis among the 2,788 patients with available BMI data to identify whether omitting obesity would affect study results. Obesity was not significantly predictive of TE (HR, 1.27, 95\% CI, 0.77-2.09) and inclusion of obesity did not affect the $\beta$ coefficients for

Table 2 Risk factors for thromboembolism in haematological malignancies

\begin{tabular}{|c|c|c|c|c|c|c|}
\hline & \multicolumn{3}{|c|}{ Univariate Cox regression } & \multicolumn{3}{|c|}{$\begin{array}{l}\text { Multivariable Cox regression }{ }^{a} \\
(n=3,368)\end{array}$} \\
\hline & HR & $95 \% \mathrm{Cl}$ & $p$-Value & HR & $95 \% \mathrm{Cl}$ & $p$-Value \\
\hline \multicolumn{7}{|l|}{ Patient-related variables } \\
\hline \multicolumn{7}{|l|}{ Age, $y$} \\
\hline Less than 1 & 1.96 & $1.01-3.79$ & 0.045 & 2.51 & $1.28-4.92$ & 0.008 \\
\hline $1-4.99$ & Ref & - & - & Ref & - & - \\
\hline $5-9.99$ & 1.72 & $1.15-2.57$ & 0.001 & 1.77 & $1.18-2.65$ & 0.006 \\
\hline $10-14.99$ & 2.46 & $1.69-3.57$ & $<0.001$ & 2.78 & $1.88-4.11$ & $<0.001$ \\
\hline Sex, male versus female & 0.97 & $0.71-1.31$ & 0.842 & 0.97 & $0.72-1.31$ & 0.040 \\
\hline Malignancy type, leukaemia versus lymphoma & 1.29 & $0.92-1.83$ & 0.144 & - & - & - \\
\hline Obesity $^{\mathrm{b}}$ & 1.52 & $0.94-2.46$ & 0.089 & - & - & - \\
\hline Diagnostic era, late versus early & 1.21 & $0.89-1.65$ & 0.222 & 1.23 & $0.91-1.67$ & 0.185 \\
\hline \multicolumn{7}{|l|}{ Treatment-related variables } \\
\hline \multicolumn{7}{|l|}{ ITR } \\
\hline 0 & 0.22 & $0.03-1.55$ & 0.130 & - & - & - \\
\hline 1 & 0.23 & $0.03-1.70$ & 0.150 & - & - & - \\
\hline $2 / 3$ & Ref & - & - & - & - & - \\
\hline 4 & 1.79 & $1.30-2.46$ & $<0.001$ & - & - & - \\
\hline $\mathrm{HSCT}$ & 1.51 & $1.02-2.23$ & 0.040 & 1.49 & $1.00-2.32$ & 0.050 \\
\hline Anthracyclines & 3.26 & $1.72-6.17$ & $<0.001$ & 2.21 & $1.12-4.37$ & 0.023 \\
\hline Asparaginase & 1.58 & $1.13-2.21$ & 0.007 & 1.68 & $1.15-2.44$ & 0.008 \\
\hline Methotrexate & 1.44 & $1.19-1.75$ & $<0.001$ & - & - & - \\
\hline Platinum agents & 1.69 & $0.42-6.79$ & 0.463 & 1.29 & $0.31-5.32$ & 0.730 \\
\hline Steroids & 2.20 & $1.22-3.95$ & 0.008 & 1.43 & $0.76-2.69$ & 0.270 \\
\hline
\end{tabular}

Abbreviations: Cl, confidence interval; HR, hazard ratio; HSCT, haematopoietic stem cell transplant; ITR, Intensity of Treatment Rating scale. aBecause of collinearity, leukaemia, methotrexate and ITR were not included in the multivariable model.

${ }^{b}$ Obesity was not included given the high rate of missing data. It was not significantly predictive of TE and inclusion of obesity did not affect the $\beta$ coefficients for the other predictor variables substantially. 
the other predictor variables substantially (data not shown). Thus, obesity was omitted from the main multivariable Cox regression model. There was collinearity between the diagnosis of leukaemia and asparaginase and methotrexate ( $r=0.66$ and $r=0.41$, respectively), between methotrexate and asparaginase and steroids $(r=0.58$ and $r=0.46$, respectively), and between ITR and HSCT $(r=0.66)$. Thus, leukaemia, methotrexate and ITR were not included in multivariable regression. Age $<1$ year, 5 to 9.99 years and 10 to 14.99 years (relative to age, $1-4.99$ years), anthracyclines, asparaginase and HSCT were significant independent positive predictors of TE in the multivariable regression.

- Table 3 shows the results of univariate and multivariable Cox proportional hazards model regression for patients with solid tumours. Among these 4,102 patients, 106 experienced a TE. In univariate analysis, the following variables were predictive of TE: metastatic status, obesity, ITR (4 vs. 2 / 3 ), surgery, radiation, anthracyclines, methotrexate, steroids and platinum agents, while CNS tumour was protective against TE. There was collinearity between ITR and HSCT and platinum agents ( $r=0.58$ and $r=0.43$, respectively). Thus, ITR was not included in the multivariable regression. Within the solid tumour group, we again created a secondary multivariable analysis to evaluate the effect of obesity among the 2,403 patients (66 TEs) with available BMI data. Obesity remained predictive of TE (HR, 1.92, 95\% CI, 1.01-3.68). Thus, - Table 3 presents two multivariable models, one (Model 1) including all solid tumour patients but not including obesity and the second (Model 2) including obesity. In Model 1 multivariable analysis $(n=4,102)$, surgery, radiation, anthracyclines and platinum agents were predictive of TE. In Model $2(n=2,403)$, surgery, radiation, anthracyclines and platinum agents were similarly significantly associated with TE and, in addition, obesity remained significantly associated with TE.

We then further explored the relationship between TE and HSCT. Forty-five of 283 patients with TE received a HSCT (15.9\%) versus 726/7,188 patients without TE (10.1\%). However, thrombosis preceded HSCT in 36/45 cases (80.0\%); 5/36 (13.9\%) patients sustained a TE recurrence after the HSCT.

Table 3 Risk factors for thromboembolism in solid tumours

\begin{tabular}{|c|c|c|c|c|c|c|c|c|c|}
\hline & \multicolumn{3}{|c|}{ Univariable Cox regression } & \multirow{2}{*}{\multicolumn{3}{|c|}{$\begin{array}{l}\text { Multivariable Cox regression } \\
\text { Model 1-without obesity } \\
(n=4,102)\end{array}$}} & \multirow{2}{*}{\multicolumn{3}{|c|}{$\begin{array}{l}\text { Multivariable Cox regression } \\
\text { Model 2-with obesity } \\
(n=2,403)\end{array}$}} \\
\hline & \multirow[b]{2}{*}{ HR } & \multirow[b]{2}{*}{$95 \% \mathrm{Cl}$} & \multirow[b]{2}{*}{$p$-Value } & & & & & & \\
\hline & & & & HR & $95 \% \mathrm{Cl}$ & $p$-Value & HR & $95 \% \mathrm{Cl}$ & $p$-Value \\
\hline Patient-related variables & & & & & & & & & \\
\hline Age, y & & & & & & & & & \\
\hline Less than 1 & 0.88 & $0.48-1.62$ & 0.687 & 0.90 & $0.47-1.73$ & 0.758 & - & - & - \\
\hline $1-4.99$ & Ref & - & - & Ref & - & - & Ref & - & - \\
\hline $5-9.99$ & 0.69 & $0.40-1.20$ & 0.188 & 0.88 & $0.49-1.56$ & 0.652 & 1.25 & $0.62-2.54$ & 0.536 \\
\hline $10-14.99$ & 1.19 & $0.75-1.88$ & 0.465 & 1.13 & $0.67-1.92$ & 0.651 & 1.53 & $0.78-3.03$ & 0.219 \\
\hline Sex, male vs. female & 0.84 & $0.58-1.24$ & 0.384 & 0.88 & $0.60-1.30$ & 0.530 & 0.79 & $0.48-1.30$ & 0.353 \\
\hline Diagnostic era, late vs. early & 0.98 & $0.67-1.44$ & 0.917 & 0.92 & $0.61-1.37$ & 0.667 & 1.02 & $0.61-1.71$ & 0.928 \\
\hline $\begin{array}{l}\text { Location, CNS vs. } \\
\text { extra-cranial }\end{array}$ & 0.28 & $0.16-0.46$ & $<0.001$ & 0.65 & $0.33-1.27$ & 0.209 & 0.51 & $0.21-1.26$ & 0.147 \\
\hline Metastatic status & 2.49 & $1.70-3.67$ & $<0.001$ & 1.03 & $0.65-1.62$ & 0.908 & 0.93 & $0.51-1.67$ & 0.803 \\
\hline Obesity $^{a}$ & 2.03 & $1.08-3.79$ & 0.027 & - & - & - & 1.92 & $1.01-3.68$ & 0.048 \\
\hline Treatment-related variables & & & & & & & & & \\
\hline ITR & & & & & & & & & \\
\hline 1 & 0.73 & $0.42-1.28$ & 0.27 & - & - & - & - & - & - \\
\hline $2 / 3$ & Ref & - & - & - & - & - & - & - & - \\
\hline 4 & 1.7 & $1.09-2.63$ & 0.02 & - & - & - & - & - & - \\
\hline Surgery & 2.26 & $1.48-3.43$ & $<0.001$ & 3.98 & $2.50-6.23$ & $<0.001$ & 2.70 & $1.44-5.08$ & 0.002 \\
\hline Radiation & 61.13 & $38.09-98.05$ & $<0.001$ & 48.40 & $28.60-81.89$ & $<0.001$ & 47.51 & $24.01-94.01$ & $<0.001$ \\
\hline $\mathrm{HSCT}$ & 1.56 & $0.89-2.73$ & 0.12 & 0.70 & $0.37-1.34$ & 0.282 & 0.66 & $0.27-1.60$ & 0.357 \\
\hline Anthracyclines & 5.77 & $3.84-8.68$ & $<0.001$ & 3.15 & $1.79-5.54$ & $<0.001$ & 2.74 & $1.29-5.82$ & 0.009 \\
\hline Methotrexate & 1.72 & $1.33-2.23$ & $<0.001$ & 1.10 & $0.78-1.57$ & 0.578 & 1.00 & $0.65-1.54$ & 0.984 \\
\hline Steroids & 1.77 & $1.21-2.60$ & 0.004 & 1.21 & $0.80-1.82$ & 0.375 & 1.20 & $0.71-2.02$ & 0.490 \\
\hline Platinum agents & 3.01 & $2.05-4.40$ & $<0.001$ & 2.13 & $1.29-3.52$ & 0.003 & 2.26 & $1.19-4.28$ & 0.013 \\
\hline
\end{tabular}

Abbreviations: $\mathrm{Cl}$, confidence interval; CNS, central system nervous; HR, hazard ratio; HSCT, haematopoietic stem cell transplant; ITR, Intensity Treatment Rating scale.

${ }^{a}$ Obesity at time of diagnosis was determined for patients $>2$ years of age with available height and weight. 
Table 4 Comparison between vascular access- and non-vascular access-related thromboembolism

\begin{tabular}{|c|c|c|c|}
\hline & $\begin{array}{l}\text { Vascular } \\
\text { access- } \\
\text { related TE } \\
N=152 \\
n(\%)\end{array}$ & $\begin{array}{l}\text { Non-vascular } \\
\text { access- } \\
\text { related TE } \\
N=131 \\
n(\%)\end{array}$ & $p$-Value \\
\hline $\begin{array}{l}\text { Median age at } \\
\text { diagnosis, } \\
\text { years (range) }\end{array}$ & $\begin{array}{l}6.7 \\
(0.0-14.0)\end{array}$ & $\begin{array}{l}7.2 \\
(0.0-14.0)\end{array}$ & 0.413 \\
\hline Male sex & $88(54.3)$ & $74(56.5)$ & 0.812 \\
\hline Diagnostic era & & & 0.693 \\
\hline Early & $58(38.2)$ & $53(40.5)$ & \\
\hline Late & $94(61.8)$ & 78 (59.5) & \\
\hline $\begin{array}{l}\text { Primary } \\
\text { diagnosis }\end{array}$ & & & 0.050 \\
\hline Leukaemia & $79(52.0)$ & $56(42.8)$ & \\
\hline Lymphoma & $26(17.1)$ & $16(12.2)$ & \\
\hline CNS tumours & $5(3.3)$ & $12(9.2)$ & \\
\hline $\begin{array}{l}\text { Extra-cranial } \\
\text { solid tumours }\end{array}$ & $42(27.6)$ & $47(35.8)$ & \\
\hline Grade & & & 0.001 \\
\hline 3 & $147(96.7)$ & $112(85.5)$ & \\
\hline 4 and 5 & $5(3.3)$ & $19(14.5)$ & \\
\hline Radiation & $53(34.9)$ & $56(42.8)$ & 0.174 \\
\hline Chemotherapy & $149(98.0)$ & $126(96.2)$ & 0.478 \\
\hline $\begin{array}{l}\text { Surgery } \\
\text { (within } 30 \mathrm{~d} \text { ) }\end{array}$ & $11(7.2)$ & $27(20.6)$ & 0.001 \\
\hline $\mathrm{HSCT}$ & $28(18.4)$ & $17(13.0)$ & 0.212 \\
\hline $\begin{array}{l}\text { Thrombosis } \\
\text { recurrence }\end{array}$ & $10(6.6)$ & $7(5.3)$ & 0.663 \\
\hline
\end{tabular}

Abbreviations: CNS, central nervous system; HSCT, haematopoietic stem cell transplantation; TE, thromboembolism.

\section{Comparison between vascular access and non- vascular access-related TE}

Among all TEs, 53.7\% were vascular access-related. - Table 4 shows the comparison between vascular access-related and non-vascular access-related TEs. Recent surgery and higher CTCAE grades of TE were associated with non-vascular access-related TEs. Nineteen recurrences of thrombosis were reported in 17 patients (recurrence rate of TE: 6.0\%); recurrence risk was not different between vascular access and non-vascular access-related TE.

\section{Discussion}

In this study, approximately $4 \%$ of children less than 15 years of age diagnosed with cancer developed a clinically significant $T E$, of which about half were vascular access-related. TEs were most common in children with leukaemia, and least common in children with CNS tumours. In children with haematological malignancies, risk factors for TEs were younger and older age relative to age 1 to 4.99 years, HSCT and exposure to anthracyclines and asparaginase. In children with solid tumours, risk factors for TEs were obesity, surgery, radiation and exposure to anthracyclines and platinum agents.

TEs are associated with increase in morbidity and mortality, as well as increased utilization of health resources, even after consideration of cancer type and stage. ${ }^{6,22,35}$ TEs can also delay or truncate cancer treatment ${ }^{18}$ and lead to CVC replacements. ${ }^{4}$ Anti-thrombotic therapy for TE is associated with adverse effects, such as increased risk of major bleeding, reported to occur between 0.3 and $24 \%$ of patients. ${ }^{5}$ TEs can also lead to chronic morbidities, such as post-thrombotic syndrome ${ }^{1}$ or, in the case of CNS thrombosis, neuro-developmental disabilities. ${ }^{2,3}$ As survival rates are increasing for most paediatric cancers, prevention of long-term morbidity is gaining greater importance. While primary thromboprophylaxis has been shown to be effective in hospitalized and ambulatory adults with cancer, ${ }^{36,37}$ these findings have not been replicated in children to date. ${ }^{26,38}$ As emphasized in our study, the incidence of TE varies depending on factors such as age, the type of cancer and treatment-related variables, and these factors appear to vary based on the underlying malignancy type. Accurate risk stratification will help to identify patients at high risk of TE and may guide clinical decision making such as when to consider thromboprophylaxis.

Our TE cumulative incidence rate falls at the lower end of previously reported incidence of symptomatic TE (between 2 and $16 \%$ ). This finding may be reflective of our stringent outcome definition, namely, TE requiring medical intervention, as well as factors specific to the Canadian paediatric oncology population, which might include the ethnic mix of patients, approaches to detection methods and cancer treatment protocols. Our incidence rate is likely to reflect the incidence rate observed in clinical settings where screening for TE in asymptomatic patients is not standard of care. However, it is possible that asymptomatic TEs may have been included in the study, if these patients received medical intervention despite the lack of symptoms.

Important inconsistencies exist in the current literature regarding TE risk factors. Several potential risk factors for TEs such as sex, diagnostic era and presence of metastatic or intra-thoracic disease had variable impact in different settings. For example, Lipay et al had identified male sex as a risk factor of TEs in cancer, ${ }^{11}$ while another study observed a non-statistically significant increase of TEs in female HSCT recipients ${ }^{22}$ and some studies found no impact of sex on TEs. ${ }^{17,18}$ Our study reaffirms the contribution of certain risk factors such as older age and underlying type of malignancy. ${ }^{7}, 11,15,17-19$ In patients with haematological malignancies, TEs followed a bimodal incidence peak, with highest risk among infants and older children, compared with children 1 to 4.99 years of age. Of note, age was not significantly associated with TEs in patients in solid tumours. Given very few reports have looked specifically at children with CNS and extra-cranial solid tumours, this observation will require confirmation in other cohorts. TEs were most frequent among patients with leukaemia, and least frequent in patients with CNS tumours, although TE-related fatalities were prominent in the CNS tumour group. Likewise, surgery was a statistically significant risk factor for TE, as previously 
demonstrated in cancer and non-cancer patients. ${ }^{39}$ We observed a strong association between radiation therapy and thrombosis in children with solid tumours that has not been reported before, although radiation therapy is known to induce endothelial inflammatory pro-thrombotic process ${ }^{40}$ leading to persistent endothelial damage. ${ }^{34}$ In a recent report from a registry of adults with cancer, $13 \%$ of TEs occurred during or after radiation. ${ }^{41}$

In our population, anthracyclines, asparaginase (haematological malignancies) and platinum agents (solid tumours) were associated with TE. The pro-thrombotic biological effects of asparaginase, by depletion of natural anticoagulants, ${ }^{42,43}$ have been well established. Anthracyclines have also been previously identified as risk factors for thrombosis. $^{20}$ Although the mechanism is not fully elucidated, anthracyclines are associated with increased expression of pro-coagulant tissue factor and exposure to phosphatidylserine $^{44}$ and increased cell-free deoxyribonucleic acid, ${ }^{45}$ resulting in increased thrombin-anti-thrombin complexes and increased thrombin generation. To our knowledge, platinum agents have not been previously reported as risk factors for thrombosis in the paediatric population, but increased thrombotic risk is described in adult patients exposed to platinums. ${ }^{33,46}$

Conversely, some risk factors were not statistically significant in our population, including the influence of sex and diagnostic era. ${ }^{17,27,47}$ Steroids, which have also been reported as a risk factor for TE in children with leukaemia, ${ }^{20}$ were not associated with TE in multivariable Cox regression. It is possible that not only is the specific agent important in increasing the risk of TE but that combination of chemotherapeutic agents may contribute to increasing TE risk. For example, steroids have been described as more potent prothrombotic agents while given concurrently with asparaginase, ${ }^{12}$ but this could not be evaluated using the available data.

Interestingly, a higher proportion of patients with TE underwent HSCT, compared with patients without TE. Exploration of the data revealed that the majority of patients sustained their first TE before their HSCT, with a substantial proportion of them experiencing a TE recurrence following HSCT. Limited evidence suggests TE is a low frequency event after paediatric $\mathrm{HSCT},{ }^{48}$ despite the HSCT-induced pro-thrombotic state. ${ }^{21}$ Our data suggest that children who were more likely to develop a $\mathrm{TE}$, based on individual predisposition or treatment-related factors, did so before the HSCT.

Our results suggest that clinically relevant TE is not a rare complication of childhood cancer, and is life-threatening or fatal in almost $10 \%$ of cases. Our findings provide an important insight into epidemiology and risk factors of thrombosis because the use of a population-based database allows for unbiased reporting of risk factors and outcomes. Our study also provides important information on cancers other than ALL, that are often too rare to be evaluated in single-centre studies.

Strengths of our study includes our large and populationbased sample size as well as the quality of information provided. In particular, the CYP-C database provided a unique richness of data regarding diagnostic and treatment informa- tion. Also, our outcome, namely, TEs requiring medical intervention, is clinically meaningful. Lastly, our study provides important information about TEs in cancer other than leukaemias, which has been previously addressed mostly in small and retrospective studies. However, our study must be interpreted in light of its limitations. Our study was limited by the paucity of information regarding thrombosis-related details. Another limitation is that CYP-C does not distinguish between arterial and venous TEs. While we believe that the majority of the events were venous TE, our sample may include arterial TEs. Also, other known risk factors of thrombosis such as blood group, recent immobilization or presence of an inherited thrombophilia were not available, and there was no information regarding use of anti-thrombotic agents. Therefore, it is unclear whether the incidence and low recurrence rates of TE are reflective, in part, of primary or secondary thromboprophylaxis. However, as primary thromboprophylaxis is currently not standard of care for any paediatric cancer patients, our estimates of the cumulative incidence of TE should be generalizable. Lastly, as with any database analysis, there is a risk of misclassification or miscoding of outcomes or predictor variables. However, CYP-C has pro-actively attempted to minimize such errors by extensive training of data abstracters and regular data audits.

In conclusion, approximately $4 \%$ of children less than 15 years of age diagnosed with cancer developed a clinically significant TE within 5 years. TEs were most common in children with leukaemia, and least common in children with CNS tumours. Among children with haematological malignancies, age at cancer diagnosis, anthracyclines and asparaginase were associated with TE, while obesity, radiation therapy, surgery, anthracyclines and platinum agents were risk factors of TEs in children with solid tumours. Surgery was more commonly associated with non-vascular accessrelated TE. Future efforts should aim towards the creation and validation of clinical prediction models to target patients at high risk of TE.

\section{What is known about this topic?}

- Thromboembolism (TE) is a well-recognized complication of cancer.

- There is conflicting information about the epidemiology of TE in children with cancer.

\section{What does this paper add?}

- The cumulative incidence at 5 years of TE requiring medical intervention was $3.8 \pm 0.2 \%$ and $0.36 \% \pm 0.07 \%$ for life-threatening or fatal TE, in a population-based study.

- In children with haematological malignancies, age, haematopoietic stem cell transplant, anthracyclines and asparaginase were associated with TE.

- In children with solid tumours, obesity, surgery, radiotherapy, anthracyclines and platinum agents were associated with TE. 


\section{Conflict of Interest}

None of the authors have competing interest to disclose. Dr. Marie-Claude Pelland-Marcotte's fellowship at the Hospital for Sick Children (Toronto, Canada) was supported by Shire Endowment Fund for Training in Pediatric Hemostasis.

\section{Acknowledgements}

The authors gratefully acknowledge the contributions of study participants, the participating paediatric oncology centres, members of the Cancer in Young People in Canada (CYP-C) Management and Steering Committees, the Pediatric Oncology Group of Ontario (POGO) and the five POGO Hospital Partners. The CYP-C is fully funded by the Public Health Agency of Canada. The authors would like to thank Randy Barber, Jaskiran Kaur and Mylène Fréchette for their help.

\section{References}

1 Polen E, Weintraub M, Stoffer C, Jaffe DH, Burger A, Revel-Vilk S. Post-thrombotic syndrome after central venous catheter removal in childhood cancer survivors: a prospective cohort study. Pediatr Blood Cancer 2015;62(02):285-290

2 Sébire G, Tabarki B, Saunders DE, et al. Cerebral venous sinus thrombosis in children: risk factors, presentation, diagnosis and outcome. Brain 2005;128(Pt 3):477-489

3 Musgrave KM, Van Delft FW, Clack RM, et al. Cerebral venous thrombosis as a complication of treatment for acute lymphoblastic leukaemia in children and young adults. Blood Conference: 56 th Annual Meeting of the American Society of Hematology, ASH 2014;124(21)

4 Kulkarni K, Halton J, Spavor M, et al. Increased requirement for central venous catheter replacement in paediatric oncology patients with deep venous thrombosis: a multicentre study. Thromb Haemost 2015;113(02):434-435

5 Monagle P, Chan AKC, Goldenberg NA, et al. Antithrombotic therapy in neonates and children: Antithrombotic Therapy and Prevention of Thrombosis, 9th ed: American College of Chest Physicians Evidence-Based Clinical Practice Guidelines. Chest 2012;141(2, Suppl):e737S-e801S

6 Forbrigger Z, Digout C, Fernandez C, Bernstein M, Kulkarni K. Significantly inferior overall and event free survival in pediatric oncology patients with symptomatic venous thrombotic events as compared to those without symptomatic venous thrombotic events: a population based study from Maritimes, Canada. Blood 2016;128(22):393

7 Asyyed Z, MacDonald T, Digout C, Kulkarni K. Incidence and characteristics of venous thrombotic events in pediatric cancer patients: a 20-year experience in the Maritimes, Canada. Pediatr Hematol Oncol 2017;34(02):90-99

8 Journeycake JM, Buchanan GR. Catheter-related deep venous thrombosis and other catheter complications in children with cancer. J Clin Oncol 2006;24(28):4575-4580

9 Khorana AA, Kuderer NM, Culakova E, Lyman GH, Francis CW. Development and validation of a predictive model for chemotherapy-associated thrombosis. Blood 2008;111(10):4902-4907

10 Khorana AA, Francis CW, Culakova E, Fisher RI, Kuderer NM, Lyman GH. Thromboembolism in hospitalized neutropenic cancer patients. J Clin Oncol 2006;24(03):484-490

11 Lipay NV, Zmitrovich AI, Aleinikova OV. Epidemiology of venous thromboembolism in children with malignant diseases: a singlecenter study of the Belarusian Center for Pediatric Oncology and Hematology. Thromb Res 2011;128(02):130-134
12 Piovesan D, Attard C, Monagle P, Ignjatovic V. Epidemiology of venous thrombosis in children with cancer. Thromb Haemost 2014;111(06):1015-1021

13 Revel-Vilk S, Yacobovich J, Tamary H, et al. Risk factors for central venous catheter thrombotic complications in children and adolescents with cancer. Cancer 2010;116(17):4197-4205

14 Schoot RA, van de Wetering MD, Stijnen T, et al; DCOG-Aristocaths Supportive Care Working Group. Prevalence of symptomatic and asymptomatic thrombosis in pediatric oncology patients with tunneled central venous catheters. Pediatr Blood Cancer 2016;63 (08):1438-1444

15 Spavor M, Halton J, Dietrich K, et al. Age at cancer diagnosis, non-O blood group and asparaginase therapy are independently associated with deep venous thrombosis in pediatric oncology patients: a risk model. Thromb Res 2016;144:27-31

16 O'Brien SH, Klima J, Termuhlen AM, Kelleher KJ. Venous thromboembolism and adolescent and young adult oncology inpatients in US children's hospitals, 2001 to 2008. J Pediatr 2011;159(01): 133-137

17 Athale U, Siciliano S, Thabane L, et al. Epidemiology and clinical risk factors predisposing to thromboembolism in children with cancer. Pediatr Blood Cancer 2008;51(06):792-797

18 Tuckuviene R, Ranta S, Albertsen BK, et al. Prospective study of thromboembolism in 1038 children with acute lymphoblastic leukemia: a Nordic Society of Pediatric Hematology and Oncology (NOPHO) study. J Thromb Haemost 2016;14 (03):485-494

19 Athale UH, Siciliano SA, Crowther M, Barr RD, Chan AK. Thromboembolism in children with acute lymphoblastic leukaemia treated on Dana-Farber Cancer Institute protocols: effect of age and risk stratification of disease. Br J Haematol 2005;129(06): 803-810

20 Caruso V, Iacoviello L, Di Castelnuovo A, et al. Thrombotic complications in childhood acute lymphoblastic leukemia: a metaanalysis of 17 prospective studies comprising 1752 pediatric patients. Blood 2006;108(07):2216-2222

21 Brandão LR, Kletzel M, Boulad F, et al. A prospective longitudinal multicenter study of coagulation in pediatric patients undergoing allogeneic stem cell transplantation. Pediatr Blood Cancer 2008; 50(06):1240-1246

22 Rangarajan HG, Stanek JR, Abu-Arja R, et al. Venous thromboembolism in pediatric hematopoietic cell transplant: a multicenter cohort study. Biol Blood Marrow Transplant 2018;24(02):337-342

23 Tabori U, Beni-Adani L, Dvir R, et al. Risk of venous thromboembolism in pediatric patients with brain tumors. Pediatr Blood Cancer 2004;43(06):633-636

24 Athale UH, Nagel K, Khan AA, Chan AK. Thromboembolism in children with lymphoma. Thromb Res 2008;122(04):459-465

25 Athale U, Cox S, Siciliano S, Chan AK. Thromboembolism in children with sarcoma. Pediatr Blood Cancer 2007;49(02):171-176

26 Mitchell LG, Andrew M, Hanna K, et al; Prophylactic Antithrombin Replacement in Kids with Acute Lymphoblastic Leukemia Treated with Asparaginase Group (PARKAA). A prospective cohort study determining the prevalence of thrombotic events in children with acute lymphoblastic leukemia and a central venous line who are treated with L-asparaginase: results of the Prophylactic Antithrombin Replacement in Kids with Acute Lymphoblastic Leukemia Treated with Asparaginase (PARKAA) Study. Cancer 2003;97(02): 508-516

27 Paz-Priel I, Long L, Helman LJ, Mackall CL, Wayne AS. Thromboembolic events in children and young adults with pediatric sarcoma. J Clin Oncol 2007;25(12):1519-1524

28 Steliarova-Foucher E, Stiller C, Lacour B, Kaatsch P. International Classification of Childhood Cancer, third edition. Cancer 2005;103 (07):1457-1467

29 Pole JD, Barber R, Bergeron RE, et al. Most children with cancer are not enrolled on a clinical trial in Canada: a population-based study. BMC Cancer 2017;17(01):402 
30 Secker D; Dietitians of Canada; Canadian Paediatric Society; College of Family Physicians of Canada; Community Health Nurses of Canada. Promoting optimal monitoring of child growth in Canada: using the new WHO growth charts. Can J Diet Pract Res 2010;71(01):e1-e3

31 Kazak AE, Hocking MC, Ittenbach RF, et al. A revision of the intensity of treatment rating scale: classifying the intensity of pediatric cancer treatment. Pediatr Blood Cancer 2012;59(01):96-99

32 Behranwala KA, Williamson RC. Cancer-associated venous thrombosis in the surgical setting. Ann Surg 2009;249(03):366-375

33 Falanga A, Marchetti M. Anticancer treatment and thrombosis. Thromb Res 2012;129(03):353-359

34 Brouwer CA, Postma A, Hooimeijer HL, et al. Endothelial damage in long-term survivors of childhood cancer. J Clin Oncol 2013;31 (31):3906-3913

35 Athale U. Thrombosis in pediatric cancer: identifying the risk factors to improve care. Expert Rev Hematol 2013;6(05):599-609

36 Akl EA, Ramly EP, Kahale LA, et al. Anticoagulation for people with cancer and central venous catheters. Cochrane Database Syst Rev 2014;(10):CD006468

37 Di Nisio M, Porreca E, Candeloro M, De Tursi M, Russi I, Rutjes AW. Primary prophylaxis for venous thromboembolism in ambulatory cancer patients receiving chemotherapy. Cochrane Database Syst Rev 2016;12:CD008500

38 Ruud E, Holmstrom H, De Lange C, Hogstad EM, Wesenberg F. Low-dose warfarin for the prevention of central line-associated thromboses in children with malignancies - a randomized, controlled study. Acta Paediatr 2006;95(09):1053-1059

39 White RH, Zhou H, Romano PS. Incidence of symptomatic venous thromboembolism after different elective or urgent surgical procedures. Thromb Haemost 2003;90(03):446-455
40 Goldin-Lang P, Niebergall F, Antoniak S, et al. Ionizing radiation induces upregulation of cellular procoagulability and tissue factor expression in human peripheral blood mononuclear cells. Thromb Res 2007;120(06):857-864

41 Guy JB, Bertoletti L, Magné N, et al; RIETE investigators. Venous thromboembolism in radiation therapy cancer patients: findings from the RIETE registry. Crit Rev Oncol Hematol 2017;113:83-89

42 Merlen C, Bonnefoy A, Wagner E, et al. L-Asparaginase lowers plasma antithrombin and mannan-binding-lectin levels: impact on thrombotic and infectious events in children with acute lymphoblastic leukemia. Pediatr Blood Cancer 2015;62(08):1381-1387

43 Staddon JH, Smock KJ, Schiffman JD, et al. Pegasparaginase treatment alters thrombin generation by modulating the protein $C$ and $\mathrm{S}$ system in acute lymphoblastic leukaemia/lymphoma. Blood Coagul Fibrinolysis 2015;26(07):840-843

44 Dong X, Shi J, Zhou J, et al. Chemotherapy induces enhanced procoagulant activity through phosphatidylserine exposure in acute lymphoblastic leukemia. Thromb Res 2013;132(05):614-620

45 Swystun LL, Mukherjee S, Liaw PC. Breast cancer chemotherapy induces the release of cell-free DNA, a novel procoagulant stimulus. J Thromb Haemost 2011;9(11):2313-2321

46 Seng S, Liu Z, Chiu SK, et al. Risk of venous thromboembolism in patients with cancer treated with Cisplatin: a systematic review and meta-analysis. J Clin Oncol 2012;30(35):4416-4426

47 Raffini L, Huang Y-S, Witmer C, Feudtner C. Dramatic increase in venous thromboembolism in children's hospitals in the United States from 2001 to 2007. Pediatrics 2009;124(04):1001-1008

48 Azık F, Gökçebay DG, Tavil B, Işık P, Tunç B, Uçkan D. Venous thromboembolism after allogeneic pediatric hematopoietic stem cell transplantation: a single-center study. Turk J Haematol 2015; 32(03):228-233 